\title{
Terapia ocupacional: uma profissão relacionada ao feminino
}

\section{Occupational therapy: a female profession}

\author{
Mirela de Oliveira \\ Figueiredo \\ Professora, Departamento de \\ Terapia Ocupacional (DTO)/ \\ Universidade Federal de São \\ Carlos (Ufscar). \\ São Carlos - SP - Brasil \\ mirelafigueiredo@gmail.com

\section{Mariana Cristina Zambulim} \\ Graduada em Terapia \\ Ocupacional, Ufscar. \\ São Carlos - SP - Brasil \\ mariknox@gmail.com

\section{Maria Luisa} \\ Guillaumon Emmel \\ Professora, Programa de \\ Pós-graduação em Terapia \\ Ocupacional (PPGTO)/Ufscar. \\ São Carlos - SP - Brasil \\ maluemmel@gmail.com

\section{Alana de Paiva Nogueira Fornereto \\ Professora, DTO/Ufscar. São Carlos - SP - Brasil \\ alanafornereto@gmail.com}

Gerusa Ferreira Lourenço

Professora, DTO; Programa de Pósgraduação em Educação Especial/ Ufscar.

São Carlos - SP - Brasil

gerusalourenco@gmail.com

Regina Helena Vitale Torkomian Joaquim Professora, DTO; PPGTO/Ufscar. São Carlos - SP - Brasil

joaquimrhvt@gmail.com

\section{Patricia Della Barba}

Professora, DTO; PPGTO; Programa de Pós-graduação em Gestão da Clínica/Ufscar.

São Carlos - SP - Brasil

patriciadellabarba@yahoo.com.br
FIGUEIREDO, Mirela de Oliveira et al. Terapia ocupacional: uma profissão relacionada ao feminino. História, Ciências, Saúde - Manguinhos, Rio de Janeiro, v.25, n.1, jan.-mar. 2018, p.115126.

Resumo

$\mathrm{O}$ artigo analisa e descreve possíveis razões pelas quais a terapia ocupacional é abordada como uma profissão feminina. Trata-se de uma revisão do tipo narrativa de caráter analítico da literatura com uma abordagem qualitativa na análise dos dados. A inserção das mulheres no mercado de trabalho esteve envolta por estereótipos associados ao gênero feminino, determinando profissões tipicamente femininas. Os estereótipos de habilidade para o cuidar e com tarefas que envolvessem movimentos finos e de bondade e paciência constituíram qualidades exigidas para as primeiras terapeutas ocupacionais e determinaram a questão do gênero na profissão. A mudança no estereótipo de gênero ocupa hoje um cenário de debates, e esta discussão pode colaborar para uma prática profissional mais reconhecida e valorizada.

Palavras-chave: profissão; feminino; terapia ocupacional; gênero.

\section{Abstract}

An analysis and description is given for the possible reasons why occupational therapy is seen as a female profession. An analytical narrative-style literature review is offered in conjunction with qualitative data analysis. The entry of women to the workplace was shrouded in stereotypes associated with the female gender, determining typically female professions. The stereotypes of skill in caregiving and tasks that required fine motor skills, kindness, and patience were the qualities required for the first occupational therapists and determined the gendered nature of the profession. Changes in gender stereotypes are today taking place in a context of debates, and this discussion could help garner greater recognition and value for the profession.

Keywords: profession; female; occupational therapy; gender. 
$\mathrm{O}$ desenvolvimento econômico e o avanço do movimento higienista no início do século XX proporcionaram uma ampliação do mercado de trabalho e a criação de novas profissões; com isso, apresentaram-se oportunidades para as mulheres (Benetton, Varela, 2001).

Nesse período, surgiu nos EUA a terapia ocupacional, profissão cujo corpo de conhecimento e práticas tinha o intuito de minimizar os efeitos da Primeira Guerra Mundial na vida de soldados que se encontravam debilitados física e mentalmente (Moreira, 2008; De Carlo, Bartalotti, 2001). O primeiro objetivo da profissão era reinserir socialmente essas vítimas da guerra, por meio do treinamento de hábitos de autocuidado e da reorganização do comportamento social. A intervenção de terapia ocupacional ocorria a partir da "utilização ativa e intencional do tempo, dividido equilibradamente entre trabalho, repouso, lazer e sono" (De Carlo, Bartalotti, 2001, p.24).

Dessa forma, a terapia ocupacional se constituiu entre os anos de 1910 e 1929, no contexto americano, marcado pelo ressurgimento do tratamento moral na psiquiatria e elevado número de ex-soldados com sequelas de guerra (Fornereto, Carretta, 2007). Em 1917 foi fundada a National Society for the Promotion of Occupational Therapy (Sociedade Nacional para Promoção da Terapia Ocupacional), posteriormente renomeada American Association of Occupacional Therapy (Associação Americana de Terapia Ocupacional) (Reed, Sanderson, 1999; Frank, 1992; Fornereto, Carretta, 2007).

Na Europa, a terapia ocupacional teve início na Inglaterra por volta de 1930, também em consequência do pós-guerra, sob responsabilidade de Elisabeth Casson, que teve contato com as escolas americanas e implementou, na Dorset House Psyquiatric Nursing Home, em Bristol, a primeira escola de formação em terapia ocupacional. Porém, a profissão foi reconhecida na Europa apenas em 1948 (Turner, 2002), e em 1952 foi organizada a World Federation of Occupational Therapy (WFOT) com a participação de representantes de associações e organizações de terapia ocupacional de dez países, a saber: Austrália, Canadá, EUA, Dinamarca, Índia, Israel, Suécia, Nova Zelândia, Reino Unido e África do Sul (WFOT, 2012). A WFOT tem tido como objetivos atuar oficialmente na organização internacional para a promoção da terapia ocupacional, defender os interesses da profissão e promover a educação e formação de terapeutas (WFOT, 2012).

Após a Segunda Guerra Mundial, a Organização Mundial de Saúde (OMS) e a Organização das Nações Unidas (ONU) procuraram países para se constituírem como referência em reabilitação e organizaram os treinamentos dos profissionais que comporiam os programas de reabilitação (Vogel, 2002). Com esse movimento iniciado pela ONU e OMS, a história da profissão inicia-se formalmente no Brasil, seguindo as estratégias de implantação de programas de reabilitação na América Latina preconizadas por organismos internacionais (De Carlo, Bartalotti, 2001).

A expansão do mercado de trabalho e do sistema educacional, ocorrida em virtude da modernização do país, gerou novas oportunidades para as mulheres, ainda que de forma excludente. Esse processo de modernização foi também acompanhado por transformações nos comportamentos afetivos e sexuais, que entraram em conflito com o padrão de valores nas relações familiares da época, sobretudo por seu caráter autoritário e patriarcal (Sarti, 2004). 
Assim, considerando-se que as mulheres tornam-se mulheres em contextos sociais e culturais específicos, a análise do movimento feminista não pode ser dissociada do contexto de sua enunciação, que lhe dá o significado.

A história do feminismo no Brasil é complexa e composta por múltiplas discussões em torno da própria história das mulheres e das construções sociais acerca do gênero (Otto, 2004). O feminismo fundou-se na tensão de uma identidade sexual compartilhada pelas mulheres em composição com a consideração da diversidade de mundos sociais e culturais nos quais a mulher se torna mulher, diversidade essa que originou a identidade de gênero, inscrita na cultura. O início do feminismo brasileiro, em 1970, foi significativamente marcado pela contestação da ordem política instituída no país com o regime militar instaurado em 1964. Em 1975, a ONU declarou o Ano Internacional da Mulher, em virtude do impacto do feminismo europeu e norte-americano, favorecendo a discussão da condição feminina no cenário internacional. Essas circunstâncias se somaram às transformações na situação da mulher no Brasil que ocorriam desde 1960, propiciadas pela modernização pela qual o país passava, colocando em questão a tradicional hierarquia de gênero. A presença das mulheres na luta armada no Brasil dos anos 1960 e 1970 implicou não apenas a insurgência contra a ordem política vigente, mas representou uma profunda transgressão ao que era designado à época como próprio das mulheres. Sem uma proposta feminista deliberada, as militantes negavam o lugar tradicionalmente atribuído à mulher ao assumirem um comportamento sexual que punha em questão, por exemplo, a virgindade e a instituição do casamento (Sarti, 2004).

As questões propriamente feministas, referentes à identidade de gênero, ganharam espaço quando se consolidou o processo de "abertura" política no país em fins da década de 1970. Nos anos 1980, o movimento de mulheres no Brasil era uma força política e social consolidada que explicitava um discurso pautado nas relações de gênero. As ideias feministas difundiram-se no cenário social do país, produto não só da atuação de suas porta-vozes diretas, mas também do clima receptivo das demandas de uma sociedade que se modernizava (Otto, 2004).

Como referido, o grande contingente de soldados enfermos após as duas guerras mundiais possibilitou que as mulheres passassem a ocupar espaço no mercado de trabalho, uma vez que a mão de obra masculina se encontrava em estado debilitado (Probst, 2003).

Acredita-se que, pela ação do cuidar estar tipicamente associada às mulheres (Vogel, Benetton, Goubert, 2002), a terapia ocupacional tornou-se uma profissão predominantemente feminina. Além disso, sabe-se que o número de homens na profissão é reduzido e sugerese que tal ocorrência se dê por um baixo interesse dos homens, relacionado à falta de perspectivas quanto a salários e reconhecimento profissional. Espera-se com este estudo poder evidenciar, por meio da retomada da história da criação da profissão, os caminhos percorridos para sua constituição e os desafios encontrados na sua consolidação, de forma a trazer para o centro desta discussão aspectos relacionados ao feminino.

Este artigo tem por objetivo analisar e descrever a história da profissão, discutindo possíveis razões pelas quais a terapia ocupacional é compreendida como uma profissão feminina. 


\section{Revisão bibliográfica}

Trata-se de um estudo de revisão do tipo narrativa de caráter analítico da literatura com uma abordagem qualitativa na análise dos dados. As pesquisas analíticas envolvem o estudo e a avaliação das informações disponíveis na tentativa de explicar o contexto de um fenômeno (Goodwin, 1995; Grant, Booth, 2009).

Para a coleta de dados, foram consultados os livros nacionais que se referiam à história da terapia ocupacional, a Revista do Centro de Estudos em Terapia Ocupacional, a base de dados Scielo, o Google Acadêmico, o Scholar Google e o American Journal of Occupational Therapy.

Nas bases de dados e periódicos pesquisados, foram utilizadas as palavras-chave "terapia ocupacional e trabalho feminino", "terapia ocupacional e gênero feminino" e suas correspondentes em inglês: occupational therapy and women's work, occupational therapy and female gender. A coleta e a captação das informações nessas bases ocorreram no período de março a maio de 2014.

Todos os capítulos de livros, artigos, monografia e dissertação encontrados que tratavam da história da terapia ocupacional, do trabalho feminino e da questão do gênero feminino na profissão foram analisados na íntegra.

Para analisar a produção científica encontrada, adotando a abordagem qualitativa (Minayo, 2010), foram elaboradas as seguintes questões: Como o modelo particular de segregação de gênero influenciou o desenvolvimento da profissão de terapeuta ocupacional? Quais os estereótipos associados à figura feminina que influenciaram o ingresso das mulheres na terapia ocupacional?

Tais questões foram produzidas a partir da literatura encontrada sobre o tema e que refere a existência de um modelo de segregação de gênero e de estereótipos relacionados à mulher. As questões produziram duas categorias temáticas para apresentação dos resultados: "Modelo particular de segregação de gênero que influenciou o desenvolvimento da terapia ocupacional" e "Os estereótipos associados à figura feminina que influenciaram o ingresso das mulheres na terapia ocupacional".

A produção científica encontrada referente à história da terapia ocupacional, ao trabalho feminino e à questão do gênero feminino na profissão constituiu-se de quatro artigos nacionais, três artigos internacionais, uma dissertação de mestrado internacional, um capítulo de livro e uma monografia, conforme os Quadros 1 e 2 ilustram:

Quadro 1: Artigos de periódicos científicos nacionais e internacionais encontrados

\begin{tabular}{|l|l|l|l|}
\hline Autor(es) & Título do artigo & Título do periódico & Ano \\
\hline Morrison Jara, R. & $\begin{array}{l}\text { “Re(conociendo) a las fundadoras y'madres' de la terapia } \\
\text { ocupacional: una aproximación desde los estudios } \\
\text { feministas sobre la ciência” }\end{array}$ & TOG & 2011 \\
\hline Moreira, A.B. & $\begin{array}{l}\text { "Terapia ocupacional: história crítica e abordagens } \\
\text { territoriais/comunitárias” }\end{array}$ & Vita et Sanitas & 2008 \\
\hline Benetton, M.J. & “Terapia ocupacional: uma profissão dos anos dourados” & Revista Ceto & 2008 \\
\hline $\begin{array}{l}\text { Vogel, B.; Benetton, } \\
\text { M.J.; Goubert, J.-P. }\end{array}$ & "Terapia ocupacional: história de uma profissão feminina” & Revista Ceto & 2002 \\
\hline
\end{tabular}


Quadro 1: Artigos de periódicos científicos nacionais e internacionais encontrados (cont.)

\begin{tabular}{|l|l|l|l|}
\hline $\begin{array}{l}\text { Benetton, M.J. } \\
\text { Varela, R.C.B. }\end{array}$ & "Eleanor Clarke Slagle" & Revista Ceto & 2001 \\
\hline Frank, G. & "Opening feminist histories of occupational therapy" & $\begin{array}{l}\text { American Journal of } \\
\text { Occupational Therapy }\end{array}$ & 1992 \\
\hline Cromwell, F.S. & "Eleanor Clarke Slagle: the leader, the woman" & $\begin{array}{l}\text { American Journal of } \\
\text { Occupational Therapy }\end{array}$ & 1977 \\
\hline
\end{tabular}

Fonte: Elaborado pelas autoras.

Quadro 2: Capítulo de livro, dissertação de mestrado e monografia encontrados

\begin{tabular}{|l|l|l|l|}
\hline Autor(es) & Título do trabalho & Tipo & Ano \\
\hline Vogel, B. & $\begin{array}{l}\text { L'ergothérapie au féminin: histoire d'une profession } \\
\text { feminine dans la France du XXème siècle }\end{array}$ & Dissertação & 2002 \\
\hline $\begin{array}{l}\text { De Carlo, M.R.P.; } \\
\text { Bartalotti, C.C. }\end{array}$ & "Caminhos da terapia ocupacional" & Capítulo de livro & 2001 \\
\hline $\begin{array}{l}\text { Fornereto, A.P.; } \\
\text { Carretta, R.Y.D. }\end{array}$ & $\begin{array}{l}\text { Sobre a "generificação" de uma profissão: percorrendo a a } \\
\text { historicidade da terapia ocupacional }\end{array}$ & Monografia & 2007 \\
\hline
\end{tabular}

Fonte: Elaborado pelas autoras.

A análise e a discussão da produção científica encontrada, adotando a abordagem qualitativa, apresentam-se, a seguir, pelas duas categorias temáticas do estudo descritas.

\section{Segregação de gênero que influenciou o desenvolvimento da terapia ocupacional}

Historicamente, a ação do cuidar sempre foi tida como feminina. Em tempos remotos, as mulheres praticavam a cura usando plantas, manipulações terapêuticas e ritos mágicos. Por dar e salvar vidas, eram vistas como fonte de sabedoria (Vogel, Benetton, Goubert, 2002).

Até por volta de 2000 a.C., as mulheres tiveram liberdade de praticar seu conhecimento da cura, mas, na Idade Média, os "físicos" (homens que se dedicavam às artes de cura) passaram a ocupar uma posição de destaque na área, inferiorizando as mulheres, que foram desencorajadas a continuar suas atividades como curandeiras, principalmente ao final do período em questão, quando, chamadas de bruxas, passaram a ser perseguidas (Vogel, Benetton, Goubert, 2002).

A partir do século XIX, as mulheres começaram a obter espaço atuando profissionalmente, e o papel de "cuidador", antes atribuído às mulheres de classe baixa, passou também a atrair mulheres de classes mais altas (Vogel, Benetton, Goubert, 2002).

No contexto internacional, na primeira metade do século XX, as primeiras trabalhadoras eram majoritariamente de classe média alta. Nessa época, poucas mulheres cursavam a faculdade com o intuito de atuar em profissões consideradas "honradas", porém, algumas estavam dispostas a frequentar alguma escola e depois fazer obras de caridade em suas comunidades, trabalhando na resolução de necessidades e em causas sociais (Frank, 1992). Como exemplo de tal fato, há registro de que mulheres foram recrutadas para cursar a 
Escola de Boston de Terapia Ocupacional por meio de anúncios nas páginas sociais de jornais reconhecidos na época (Cromwell, 1977).

A história da enfermagem propicia a análise do início da terapia ocupacional e de como o modelo particular de segregação de gênero influenciou o desenvolvimento da profissão. Por volta de 1890, nos EUA, havia muitas enfermeiras, e a maioria realizava atendimentos particulares. No início do século XX, com a evolução da medicina hospitalar, ocorreu uma diminuição pela procura dos serviços de enfermagem. Com isso, as enfermeiras passaram a realizar especializações em linhas auxiliares de trabalho, e não mais estritamente ligadas à enfermagem. Nesse momento, algumas enfermeiras se especializaram em terapia ocupacional (Frank, 1992; Reed, Sanderson, 1999).

Tal fato também ocorreu com o serviço social. Em 1911, por exemplo, a assistente social Eleanor Clarke Slagle concluiu o curso sobre "ocupação e recreação", oferecido pela primeira vez em 1908, voltado para as ocupações recreativas e curativas na área da saúde. Ainda em 1911, Slagle passou a ministrar um curso similar no Hospital Estadual de Newberry (Benetton, Varela, 2001). Slagle pertencia à classe média alta e era da família de Theodore Roosevelt, na ocasião presidente dos EUA. O irmão de Slagle, John Clarke, era um congressista republicano, logo, ela era ligada à política de Nova York e tinha algum poder institucional (Frank, 1992).

As mulheres fundadoras da terapia ocupacional, também inspiradas no Movimento Arte e Artesanato, foram a enfermeira Susan E. Tracy, a professora Susan C. Johnson e a já citada assistente social Eleanor Clarke Slagle. A visibilidade dessas mulheres ocorreu por meio da posição social que ocupavam (Frank, 1992).

Lopes (1999) refere que o recrutamento dos terapeutas ocupacionais, nos EUA, Inglaterra e Canadá, era realizado pelos critérios de seleção do tipo "moral", em que mais importava o "caráter" do que quaisquer conhecimentos técnicos especializados.

A partir de 1950, há mudanças nos padrões culturais, e as mulheres entram no mercado de trabalho em setores como escritórios, comércio ou serviços públicos, e é nesse processo de inserção no mercado de trabalho, mesmo que ainda incipiente, que nasce a terapia ocupacional (Benetton, 2008).

Assim, o início formal da terapia ocupacional nos EUA é marcado pela presença e visibilidade de mulheres de classe média alta, vinculadas a profissões organizadas que já aceitavam mulheres, como a enfermagem e a assistência social. Com o término da Primeira Guerra Mundial e com a grande crise econômica norte-americana de 1929, gradualmente o percentual de terapeutas ocupacionais se expandiu para além da classe média alta, uma vez que, em inúmeras famílias, o responsável por prover o sustento era um ex-soldado que se encontrava incapacitado fisicamente ou desempregado, em razão das inúmeras falências de indústrias e empresas que ocorreram na época (Frank, 1992).

Dessa forma, o pós-guerra viabilizou a presença feminina como mão de obra disponível para o trabalho, uma vez que havia muitos soldados feridos nas frentes de batalha requerendo cuidados. A mulher foi considerada adequada para fornecer esses cuidados, já que possuía competências prévias para tal função (Frank, 1992).

A origem da terapia ocupacional como profissão está relacionada, portanto, com os acontecimentos históricos, sociais e econômicos da época de seu surgimento, 
acompanhando o dinamismo e evolução desses processos e do ser humano (Neistadt, Crepeau, 2002).

No Brasil, a década de 1950 constituiu a gênese de diversas profissões da área da saúde em virtude da implantação de programas de reabilitação, fruto do movimento internacional de reabilitação. Dentre essas profissões se encontrava a terapia ocupacional, atuando na área de reabilitação física em nível técnico (Soares, 2007).

Com isso, a implantação da terapia ocupacional no cenário nacional seguiu o modelo norte-americano no que se refere à formação, aos conhecimentos teóricos e aos objetivos da prática (De Carlo, Bartalotti, 2001). Subentende-se que o perfil profissional, ou seja, ser uma profissão constituída por mulheres, também foi introjetado no Brasil.

Entretanto, o perfil social, político e econômico das profissionais brasileiras, no período de implantação da profissão, era distinto daquele do contexto internacional no qual se originou e se desenvolveu a terapia ocupacional, o que exige uma breve descrição para a análise da questão do gênero feminino no Brasil.

No Brasil, a partir da década de 1970, com a expansão da economia e o acelerado processo de industrialização e urbanização, intensificou-se a participação das mulheres no mercado de trabalho. Tal fato manteve-se na década de 1980, mesmo com a estagnação econômica e a deterioração das oportunidades de emprego. A tendência da crescente participação da mulher no mercado de trabalho permaneceu nos anos 1990, período caracterizado pela intensa abertura econômica, pelos baixos investimentos e pela terceirização da economia (Hoffmann, Leone, 2004).

A partir da inserção da mulher no mercado de trabalho, nos espaços públicos e nas universidades, o que viabilizou novas oportunidades de trabalho, ocorreu uma consequente diminuição na taxa de fecundidade (Bruschini, Lombardi, 2010). Dessa forma, se ao final dos anos 1970 as trabalhadoras eram jovens e sem filhos, ao final dos anos 1980 passaram a ser mães, casadas e mais velhas. Com a porcentagem expressiva de mulheres casadas economicamente ativas, a família deixou de ser empecilho para sua inserção no mercado de trabalho. No entanto, o despendimento com os cuidados domésticos e dos filhos, se configurando ainda como responsabilidade quase única da mulher, causa interferência nessa inserção (Bruschini, 2000a, 2000b). Além disso, o restrito número de equipamentos de apoio, como creches, obriga as mulheres a dedicarem mais tempo de si para o lar. Tais fatos reforçam a influência da maternidade como obstáculo para o ingresso das mulheres no mercado de trabalho (Bemfam, 1997).

No que se refere à escolaridade, até o final da década de 1990, segundo dados do Ministério da Educação (MEC/Inep, 2000), notou-se uma igualdade de gênero até os 8 anos, que se refere ao ensino fundamental. A partir do ensino médio, as mulheres possuíam nível de escolarização até 55\% mais elevado em relação aos homens. Isso foi justificado pelo fato de os homens ingressarem no mercado de trabalho antes que as mulheres, uma vez que elas, muitas vezes, se dedicavam ao trabalho doméstico. Os horários de trabalho formal eram incompatíveis com os de estudos, ao passo que o trabalho doméstico possui horários mais compatíveis com os escolares (Rosemberg, 1989; Madeira, 1997).

Essa aquisição de escolaridade pelas mulheres propiciou maiores chances para o ingresso e a permanência no mercado de trabalho. Entretanto, ao se analisar os percentuais 
femininos por áreas do conhecimento, observa-se que, tanto no ensino técnico e profissional quanto no nível superior, persistiam determinadas opções femininas que se reproduziam, posteriormente, no mercado de trabalho. Dessa forma, um número significativo de mulheres se dirigia para a profissionalização em funções tipicamente femininas, em cursos técnicos ou superiores, predominando a área da saúde e o funcionalismo público (Bruschini, Lombardi, 2010).

Fornereto e Carretta (2007) e Vogel, Benetton e Goubert (2002) referem que a habilidade para cuidar e os cuidados já realizados no ambiente domiciliar, características consideradas femininas, constituíram fatores para aproximação do gênero feminino com a profissão de terapeuta ocupacional.

Testa e Spampinato (2010) acrescentam que a criação da carreira de terapeuta ocupacional esteve influenciada por um sistema de gênero que estabeleceu hierarquias, privilégios e desigualdades, delimitando o campo profissional a um universo considerado "naturalmente" feminino, constituído por atividades de vida diária, atividades artesanais e manuais, cuidado das crianças e uma parcela de amor e abnegação, a fim de levar adiante o desafio da reabilitação.

Nesse sentido, reforça-se a proximidade com as atividades cotidianas como fator para o ingresso das mulheres na formação em terapia ocupacional e exercício da profissão no Brasil (Lopes, 1999).

Nesse contexto, paulatinamente, a mulher adentra os espaços públicos e se apropria do extradomiciliar, mas ainda restrita a profissões que, na sua concretização, tinham proximidade com as atividades desempenhadas no intradomiciliar. Dessa forma, o perfil do terapeuta ocupacional, em dado momento da história da profissão, foi delineado seguindo como critério os papéis que eram esperados da mulher na sociedade para o exercício da profissão (Fornereto, Carretta, 2007).

\section{Estereótipos femininos que influenciaram o ingresso das mulheres na terapia ocupacional}

Como referido anteriormente, as primeiras terapeutas ocupacionais foram mulheres. Em 1918 cerca de duzentas mulheres civis norte-americanas, enfermeiras e/ou assistentes sociais, especializadas em terapia ocupacional, foram enviadas à França pelo exército dos EUA para trabalhar como auxiliares da reconstrução, cuidando dos feridos de guerra. A elas foram delegadas a promoção da motivação e a elevação da moral dos homens no pós-guerra. Inicialmente, o salário base de uma auxiliar da reconstrução era de cinquenta dólares, sendo aceitas apenas mulheres solteiras. Era uma renda atrativa na época, mas não o bastante para o sustento de uma família, o que denota o menor reconhecimento do trabalho feminino em relação ao masculino (Frank, 1992).

Vogel (2002) aponta que Dunton, Barton e Kjdner postulavam que o papel de prover o cuidado e o tratamento por meio de atividades era específico das mulheres, pois consideravam que estas possuíam o instinto materno do cuidar, essencial para trabalhar com terapia ocupacional. A mulher foi então relegada ao papel de assistente de execução, tendo os homens, médicos, o poder de decisão. Essa atitude sexista levou as assistentes a 
internalizar o estado de submissão e inferioridade. A mulher na época deveria se sentir atraída por cuidar dos desfavorecidos, não ambicionando maior poder ou status e, dessa forma, mantendo-se na posição de "segundo" sexo (Vogel, 2002).

Slagle, considerada a criadora da terapia ocupacional, dedicou parte de seu trabalho a descrever a personalidade de uma terapeuta ocupacional ideal. Seria uma mulher paciente, de bondade infinita, como uma mãe que tem uma criança pequena e a trata oferecendo liberdade ao mesmo tempo que aponta as responsabilidades e proporciona a capacidade de explorar o mundo (Benetton, Varela, 2001).

Dessa forma, Slagle construiu o estereótipo de uma terapeuta ocupacional com referência à paciência e à maternidade, características que eram socialmente atribuídas às mulheres (Frank, 1992). Ela enfatizava a expressão física apropriada, voz agradável, gentileza, honestidade, paciência, além de infinita bondade, como qualidades que as terapeutas ocupacionais deveriam ter para desenvolver um bom trabalho (Morrison Jara, 2011).

Na história da enfermagem é possível notar uma abordagem que faz referência a uma mulher com dotes estereotipados de feminilidade (Padilha, Vaghetti, Brodersen, 2006).

Nesse período a mulher era vista como um ser "apolítico", participando pouco da vida social, sendo essa ação promovida apenas pelos homens. À mulher delegavam-se tarefas consideradas próprias para elas, como os encargos de mantedora familiar, cuidando dos filhos, do marido, dos irmãos e pais. No que diz respeito à terapia ocupacional, tais ações constituíam uma espécie de extensão do mundo da mulher, levando à sua profissionalização, uma vez que o cuidar era considerado essencial para a melhora dos pacientes (Fornereto, Carretta, 2007).

Na década de 1950, nos EUA, a terapia ocupacional era vista como uma profissão boa para as mulheres, uma vez que podiam conciliar trabalho e cuidar da casa. Já na década de 1970, muitas mulheres abandonaram a profissão antes de se tornarem mães, pois a gravidez constituía a principal razão para que houvesse abandono do trabalho (Vogel, 2002).

Além das atividades domésticas voltadas somente às mulheres, a história mostra que a elas também se destinavam ações relacionadas com habilidades manuais, como bordado e artesanato. Em contrapartida, aos homens destinavam-se tarefas de coordenação motora global, que exigiam maior força. Foi por meio dessa visão de afazeres que se consistiu a reabilitação física no campo da terapia ocupacional, sendo que uma boa terapeuta deveria ter conhecimento de tricô, trabalhos em madeira, costura e cestaria, promovendo dessa forma a distração de pacientes (Fornereto, Carretta, 2007).

As fundadoras da terapia ocupacional lutaram para que a mulher tivesse uma inserção significativa na vida pública e no mundo do trabalho (Frank, 1992).

Ao longo da história, constituiu-se um desafio para as mulheres conciliar os afazeres da casa, o cuidado com os filhos e o trabalho. A terapia ocupacional é uma profissão vista como provedora desse equilíbrio, pois é filosoficamente preparada para ajudar a desenvolver soluções criativas para tais requisitos (Vogel, 2002).

$\mathrm{Na}$ atualidade, o enraizamento da presença feminina na profissão ainda é observável. Vogel (2002) refere que algumas das razões para que ainda não haja interesse masculino pela profissão seriam a falta de perspectiva financeira e o baixo status. No geral, os homens 
denotam interesse por profissões que ofereçam maiores garantias de poder, e a sociedade ainda aponta que trabalhos manuais, como os que a terapia ocupacional utiliza em seu setting terapêutico, são destinados às mulheres.

O cuidar ainda é uma ação hegemonicamente feminina, porém a mulher atual saiu do ambiente doméstico e estabeleceu uma inversão de papéis. Nas universidades se observam as pluralidades em diversos campos de atuação (Fornereto, Carretta, 2007).

Rider e Brashear (1988) adotam o mesmo argumento para justificar a ausência de homens na terapia ocupacional e afirmam que mulheres estão cada vez mais demonstrando interesse por profissões tidas como masculinas. Apesar de ainda sofrerem com a discriminação de gênero, as mulheres consideram que essas profissões garantem maior segurança, oportunidades de progresso e melhores condições de trabalho.

Segundo estudos realizados na década de 1980, a profissão contava com cerca de 5\% de homens, sendo que $80 \%$ deles tinham emprego em tempo integral e, dessa porcentagem, $34,2 \%$ atuavam na área de disfunção física, 20,6\% na área de disfunção psicossocial, 6,2\% em ambiente escolar, 4,7\% eram educadores e 14,5\% trabalhavam em outras áreas. Além disso, os estudos revelam que, apesar do baixo índice de homens na profissão, eram eles que publicavam mais artigos, ocupavam mais cargos de liderança e atuavam como diretores e presidentes de associações. A justificativa para a baixa porcentagem de homens na terapia ocupacional estava no fato de a profissão não oferecer perspectivas de crescimento, além de pagar salários baixos e conferir pouco prestígio social. Os fatores mais apontados pelos homens para trabalhar como terapeuta ocupacional foram a oportunidade de atuar com pessoas, a possibilidade de usar habilidades especiais, a disponibilidade de trabalho e a oportunidade de assumir posições de liderança (Rider, Brashear, 1988).

Não foram encontrados estudos que discutissem o lugar do homem na terapia ocupacional na atualidade. Nesse sentido, se faz necessária a realização de estudos que estimem a presença masculina na profissão e avaliem em quais áreas e contextos estão inseridos. Sabe-se que a terapia ocupacional não é uma profissão só para as mulheres e presume-se que, para haver o maior número de homens na profissão, seja necessário mudar o status e o reconhecimento estabelecido por ela, melhorar as condições salariais e aumentar as perspectivas de progresso e segurança.

\section{Considerações finais}

O processo de criação da terapia ocupacional como profissão coincide historicamente com o momento de entrada das mulheres em profissões femininas que, posteriormente, demandaram maior qualificação profissional.

O modelo de segregação de gênero influenciou o desenvolvimento de diversas profissões direcionadas às mulheres, como a terapia ocupacional, uma vez que requeriam a concretização de ações e papéis esperados pela mulher na sociedade.

Os estereótipos associados à figura feminina, como a habilidade para "o cuidar" e para realizar tarefas que envolvessem movimentos finos associados às características de bondade infinita e paciência, constituíram qualidades exigidas para as primeiras terapeutas ocupacionais e influenciaram a questão do gênero feminino na terapia ocupacional. 
A mudança no estereótipo de gênero já se iniciou, mas constitui um caminho a ser trilhado e que propicia paulatinamente uma prática mais reconhecida e valorizada.

Os profissionais da atualidade podem colaborar na formação dos que virão, apresentando as potencialidades da terapia ocupacional como um todo, quebrando tabus e gerando maiores possibilidades de compartilhamento entre gêneros. Para tal, considera-se importante incluir na grade curricular a história da terapia ocupacional envolvendo a questão da participação das mulheres nessa construção e relacionando-a com os específicos contextos social, histórico e cultural.

Por fim, a realização deste estudo possibilitou conhecer algumas hipóteses que têm sido levantadas em estudos e textos publicados por terapeutas ocupacionais ou outros estudiosos do campo da saúde, relativos à terapia ocupacional como profissão feminina. Entretanto, por se tratar de uma revisão bibliográfica e com um número limitado de publicações encontradas, contém limitações, e por isso se faz necessário, para uma compreensão da complexa realidade histórica, que sejam realizados novos estudos, incluindo pesquisas de campo com entrevistas e pesquisa documental para verificação dessas hipóteses sob outras perspectivas e para maior fidedignidade dos dados.

\section{REFERÊNCIAS}

\section{BEMFAM.}

Sociedade Civil de Bem-Estar Familiar no Brasil. Pesquisa Nacional sobre Demografia e Saúde (PNDS), 1996. Disponível em: http://pt.scribd. com/doc/22518211. Acesso em: 18 fev. 2014. 1997.

BENETTON, Maria J.

Terapia ocupacional: uma profissão dos anos dourados. Revista CETO, n.11, p.3-17. 2008.

BENETTON, Maria J.; VARELA, Renata C.B. Eleanor Clarke Slagle. Revista CETO, n.6, p.3235. 2001.

\section{BRUSCHINI, Cristina.}

Gênero e trabalho no Brasil: novas conquistas ou persistência da discriminação? (Brasil, 1985-95). In: Rocha, Maria I.B. (Org.). Trabalho e gênero: mudanças, permanências e desafios. Campinas: Editora 34; Abep; Nepo-Unicamp; Cedeplar-UFMG. p.13-18. 2000a.

BRUSCHINI, Cristina.

A situação da mulher brasileira nas últimas décadas. In: Velloso, João P.R. (Org.). Brasil 500 anos: futuro, presente e passado. Rio de Janeiro: José Olympio. p.423-464. 2000b.

BRUSCHINI, Cristina; LOMBARDI, Maria R. O lugar das mulheres no mercado formal de trabalho. In: Fundação Carlos Chagas. Banco de dados sobre o trabalho das mulheres. Séries históricas, 7. Disponível em: http://www.fcc.org. br/bdmulheres/serie7.php?area=series. Acesso em: 18 fev. 2014. 2010.
CROMWELL, Florence S.

Eleanor Clarke Slagle: the leader, the woman. American Journal of Occupational Therapy, v.31, n.10, p.645-648. 1977.

DE CARLO, Marysia M.R.P.; BARTALOTTI, Celina C.

Caminhos da terapia ocupacional. In: De Carlo, Mariysia M.R.P.; Bartalotti, Celina C. (Org.). Terapia ocupacional no Brasil: fundamentos e perspectivas. São Paulo: Plexus. p.19-40. 2001.

FORNERETO, Alana P.N.; CARRETA, Regina D. Sobre a "generificação" de uma profissão: percorrendo a historicidade da terapia ocupacional. Monografia (Graduação em Terapia Ocupacional) - Faculdade de Medicina de Ribeirão Preto, Universidade de São Paulo, Ribeirão Preto. 2007.

FRANK, Gelya.

Opening feminist histories of occupational therapy. American Journal of Occupational Therapy, v.46, n.11, p.11989-11999. 1992.

GOODWIN, James C.

Research in psychology: methods and design. New York: John Wiley. 1995.

GRANT, Maria J.; BOOTH, Andrew.

A typology of reviews: an analysis of 14 review types and associated methodologies. Health Information and Libraries Journal, v.26, p.91-108. 2009.

HOFFMANN, Rodolfo; LEONE, Eugenia T. Participação da mulher no mercado de trabalho 
e desigualdade da renda domiciliar per capita no Brasil, 1981-2002. Nova Economia, v.14, n.2, p.35-58. 2004.

LOPES, Roseli E.

Cidadania, políticas públicas e terapia ocupacional, no contexto das ações de saúde mental e saúde da pessoa portadora de deficiência no município de São Paulo. Tese (Doutorado em Educação) Universidade Estadual de Campinas, Campinas. 1999.

MADEIRA, Felícia R.

A trajetória das meninas dos setores populares: escola, trabalho... ou reclusão. In: Madeira, Felícia R. (Org.). Quem mandou nascer mulher? Estudos sobre crianças e adolescentes pobres no Brasil. Rio de Janeiro: Record; Rosa dos Tempos. p.45-134. 1997.

\section{MEC/INEP.}

Ministério da Educação. Instituto Nacional de Estudos e Pesquisas Educacionais. Sinopse estatística da educação básica: censo escolar 99. Brasília: Inep. Disponível em: http://portal.inep. gov.br/basica-censo-escolar-sinopse-sinopse. Acesso em: 20 jul. 2014. 2000.

MINAYO, Maria Cecília de Souza.

O desafio do conhecimento: pesquisa qualitativa em saúde. São Paulo: Hucitec; Abrasco. 2010.

MOREIRA, Adriana B.

Terapia ocupacional: história crítica e abordagens territoriais/comunitárias. Vita et Sanitas, v.2, n.2, p.79-90. 2008.

MORRISON JARA, Rodolfo.

Re(conociendo) a las fundadoras y 'madres' de la terapia ocupacional: una aproximación desde los estudios feministas sobre la ciencia. TOG, v.8. n.14. Disponível em: http://www. academia.edu/3786033/Reconociendo_A_ Las_Fundadoras_Y_Madres_De_La_Terapia_ Ocupacional. Acesso em: 12 jul. 2014. 2011.

NEISTADT, Maureen E; CREPEAU, Elizabeth Blesedell.

Willard and Spackman Terapia Ocupacional. Rio de Janeiro: Guanabara Koogan. 2002.

OTTO, Claricia.

O feminismo no Brasil: suas múltiplas

faces. Estudos Feministas, v.12, n.2, p.238-241.

Disponível em: http://www.scielo.br/scielo. php?script=sci_arttext $\&$ pid=S0104-026X2004 $000200015 \& \operatorname{lng}=$ en \& $n r m=i s o$. Acesso em: 20 ago. 2016. 2004.

PADILHA, Maria I.C.S.; VAGHETTI, Helena H.; BRODERSEN, Gladys.

Gênero e enfermagem: uma análise reflexiva. Revista de Enfermagem, v.14, n.2, p.292-300. 2006.
PROBST, Elisiana R.

A evolução da mulher no mercado de trabalho. Revista Leonardo Pós, n.2. Disponível em: http:// www.posuniasselvi.com.br/artigos/rev02-05. pdf. Acesso em: 20 jul. 2014. 2003.

REED, Kathlyn L.; SANDERSON, Sharon.

The philosophical base. In: Reed, Kathlyn L.; Sanderson, Sharon. Concepts of occupational therapy. Baltimore: Williams and Wilkins. p.330. 1999.

RIDER, Barbara A.; BRASHEAR, Robert M. Men in an occupational therapy. The American Journal of Occupational Therapy, v.42, n.2, p.231237. 1988 .

ROSEMBERG, Fulvia.

$2^{\circ}$ grau no Brasil: cobertura, clientela e recursos. Cadernos de Pesquisa, n.68, p.39-54. 1989.

SARTI, Cynthia Andersen.

O feminismo brasileiro desde os anos 1970: revisitando uma trajetória. Estudos Feministas, v.12, n.2, p.35-50. Disponível em: http://www. scielo.br/pdf/ref/v12n2/23959.pdf. Acesso em: 20 jul. 2016. 2004.

SOARES, Lea Beatriz Teixeira.

História da terapia ocupacional. In: Cavalcanti, Adriana; Galvão, Claudia. Terapia ocupacional: fundamentação e prática. Rio de Janeiro: Guanabara Koogan. p.3-9. 2007.

TESTA, Daniela E.; SPAMPINATO, Sandra B. Género, salud mental y terapia ocupacional: algunas reflexiones sobre la influencia de la historia de las mujeres y la perspectiva de género en nuestras prácticas. Revista de Terapia Ocupacional da Universidade de São Paulo, v.21, n.2, p.174-181. 2010.

TURNER, Annie.

History and philosophy of occupational therapy. In: Turner, Annie; Foster Marg; Johnson, Sybil E. Occupational therapy and physical dysfunction. London: Churchill Livinsgtone. p.3-10. 2002.

VOGEL, Beatriz.

L'ergothérapie au féminin: histoire d'une profession feminine dans la France du XXème siècle. Dissertação (Mestrado em História da Saúde) - École des Hautes Études en Sciences Sociales, Paris. 2002.

VOGEL, Beatriz; BENETTON, Maria J.; GOUBERT, Jean-Pierre.

Terapia ocupacional: história de uma profissão feminina. Revista CETO, n.7. 2002.

WFOT.

World Federation of Occupational Therapies. History. Disponível em: http://www.wfot.org/ AboutUs/History.aspx. Acesso em: 20 fev. 2014. 2012. 